7-17-2020

\title{
A Revised Logic Model for Educational Program Evaluation
}

Zsa-Zsa Booker

Wayne State University School of Medicine, zsazsabooker@gmail.com

Follow this and additional works at: https://digitalcommons.wayne.edu/jmasm

Part of the Applied Statistics Commons, Social and Behavioral Sciences Commons, and the Statistical Theory Commons

\section{Recommended Citation}

Booker, Z-Z. (2019). A Revised Logic Model for Educational Program Evaluation. Journal of Modern Applied Statistical Methods, 18(2), eP3047. https://doi.org/10.22237/jmasm/1604190300

This Quantitative Program Evaluation is brought to you for free and open access by the Open Access Journals at DigitalCommons@WayneState. It has been accepted for inclusion in Journal of Modern Applied Statistical Methods by an authorized editor of DigitalCommons@WayneState. 


\section{SPECIAL SECTION ON QUANTITATIVE PROGRAM EVALUATION A Revised Logic Model for Educational Program Evaluation}

\section{Zsa-Zsa Booker}

Wayne State University School of Medicine Detroit, MI

The logic model is an evaluation tool popularly used for obtaining grant funding. Its limitations make it unlike other theory driven evaluation methods. A critical examination of the logic model leads to the construction of an enriched revised logic model.

Keywords: $\quad$ evaluation, logic model, program evaluation

\section{Introduction}

As evidence of the changing grant requirements in the U. S. Department of Education and various other funding and accreditation entities, program evaluation has grown in popularity over the years. This evidence of growth is seen from foundations such as of America, W.K. Kellogg Foundation, and the Annie E. Casey Foundation, where the use of a logic model is required to compete for grants each year (Fitzpatrick, Sanders, \& Worthen, 2012; Stufflebeam, 2001). The logic model is based on a diagram demonstrating how a program will function based on different environmental conditions The elements of a logic model are inputs, activities, outputs, and outcomes (Wholey, Hatry, \& Newcomer, 2010). It is considered an easy model to understand based on its design with built-in diagrams that display information about a program (W. K. Kellogg Foundation, 2004). The use of logic models has steadily increased over the years, and programs and organizations are being challenged more by all levels of federal government to describe their program's story in a way that effectively presents the program's outcome goals and the achievement of these goals (Wholey et al., 2010).

doi: 10.22237/jmasm/1604190300 | Accepted: October 9, 2018; Published: July 17, 2020.

Correspondence: Zsa-Zsa Booker, zsazsabooker@gmail.com 


\section{ZSA-ZSA BOOKER}

The W. K. Kellogg Foundation (2004) noted the logic model is a depiction of how an organization does its work, which consists of the theory and assumptions underlying the program. It links outcome with program activities or processes or both with the theoretical assumptions and or principles of the program. Frechtling (2007) provided a different definition: "The logic model is a tool that describes the theory of change underlying an intervention, product, or policy. It characterizes a project through a system of elements that include components and connections, with context being an important qualification" (Frechtling, 2007, p. 1).

The logic model is sometimes compared to the hypothesis in a research study. Programs are regarded as a hypothesis, and when a program is implemented, the expected results follow. Logic models are tools used to unpack the hypothesis (Wholey et al., 2010). Logic models are diagrams that display components of a program and its theory, and they can be helpful for program planning, evaluation, and research (OAERS, n.d.). By definition, a logic model is a graphical representation of a program and is referred to as an evaluability assessment or a feasibility analysis. Relationships are described between objectives, activities, indicators, and resources of a program (Dwyer \& Makin, 1997). Renger and Titcomb (2002) noted a logic model is an essential first step in program evaluation, a visual representation of a plausible and sensible method of how a program will work under certain conditions to solve identified problems, and it is fundamental to program evaluation.

The U. S. federal government awards nearly $\$ 400$ billion annually in grants for most of the nation's educational, health, social welfare, housing, environmental, criminal justice, and transportation programs. However, this money is not enough to address the complexity of the growing national priorities due to the constant decrease in funding allocations (Polush, 2007). Historically, accountability due to limited funding was obtained via program evaluation (Stake, 1976). This helps granting agencies with the task of making difficult decisions regarding funding for the nation's social services and other programs. Funding has to be divided among competing needs, and it is vital that evaluation studies are present in order to identify costs and benefits of those programs (Stake, 1976). The fight for government funding is very competitive which makes logic model research even more relevant and vital because many government funded grants require logic modeling in order to qualify for funding initially or to qualify for funding renewal (Chen, 2015). 


\section{REVISED LOGIC MODEL FOR PROGRAM EVALUATION}

\section{Weaknesses of the Logic Model}

Stufflebeam (2001) critiqued the logic model's weaknesses and limitations as the following:

1. May undesirably narrow the range of the program services.

2. Evaluators might take over the program staff's responsibility for program design.

3. May ground an evaluation in a hastily developed, inadequate program theory.

4. May develop conflict of interest to defend the evaluation-generated program theory.

5. Might bog down the evaluation in a seemingly endless process of program theory development.

6. May create a theory early in a program and impede the program from redefinition and refinement.

Many of these limitations pertain to program theory development, and others are more concerned with the identification of services offered and the development of the program design.

\section{Purpose of the study}

The logic model is missing key elements that are present in other similar models which could help to make the logic model more comprehensive and effective. In order to address limitations of the logic model, a revised logic model and logic model flow-chart will be designed and serve as a guide to be followed throughout the logic model evaluation process. The W.K. Kellogg Foundation (2004) provided sample checklists and flow charts for logic model development, which will be used to develop the revised logic model and the logic model flow chart.

Similarly, a template for the logic model created by the United Way of America was used as the resource for an enriched logic model. The logic model created by United Way of America is more of a conceptual model which allows for the most adaptation and can be easily transformed to fit a wide array of programs (W.K. Kellogg Foundation, 2004). To help remedy some of the logic model limitations and lack of standards, a revised logic model was created based on the evaluation standards created by the Joint Committee on Standards for Educational Evaluation (1994). 


\section{ZSA-ZSA BOOKER}

\section{Method}

The methodology was divided into three different sections. The first section focused on the development of the newly revised logic model. The second section described the procedures for testing both the original and newly revised logic model. Lastly, the third section described the meta-evaluation and analysis of the two logic models after they had been used and applied to the learning community educational program. The purpose of the last phase, which relates to the main research question, is used to help determine which logic model is more effective.

The revisions to the original logic model were based on the Joint Committee on Standards for Educational Evaluation (1994) and Stufflebeam's (2001) research. After the revised logic model was designed, it was used to evaluate a learning community educational program, within a midwestern higher education institution. In order to compare the original logic model to the revised logic model. The purpose of the evaluation of the learning community was to determine the effectiveness of the learning community educational program at a midwestern higher education institution.

\section{Development of the Newly Revised Logic Model}

The United Way of America logic model is comprised of four main components: inputs, activities, outputs and outcomes. The revised logic model, like the original model, will also include these components. However, in addition to the characteristics seen in the original logic model, the revised logic model will also include a logic model flow chart, program theory identification/validation check and theory research components prior to its use, the use of Chi-Square test for data analysis, rejection of artificial cut scores, and consideration for contextual influences.

\section{Development Procedures}

In order to create the revised logic model, research was conducted to discover some of the most relevant and repeatedly stated limitations offered by evaluation professionals. These limitations were considered along with the logic model limitations offered by Stufflebeam (2001). The limitations of the logic model that are important to this study are unidentified program theory, program services, and program design; the logic model is better practiced as a framework, instead of an evaluation model or method; it can be time consuming and costly to develop a logic model; other theory-based models, similar to the logic model, use statistical 


\section{REVISED LOGIC MODEL FOR PROGRAM EVALUATION}

methods in order to analyze the data used in the evaluation; other theory-based models, similar to the logic model, reject the use of artificial cut scores; other theory-based models, similar to the logic model, consider the use of contextual influences.

Utility standards help to assure that stakeholders find program evaluation processes valuable to their needs (Joint Committee on Standards for Educational Evaluation, 1994). More specifically, this change helped to improve Utility Standard Number 7, timely and appropriate communicating and reporting, which states that evaluations should adapt to the information needs of their audiences (Joint Committee on Standards for Educational Evaluation, 1994). The ast step in the newly revised logic model flow chart, meta-evaluation/evaluation review, helped to improve the evaluation accountability standards provided by the Joint Committee on Standards for Educational Evaluation (1994). More specifically, the evaluation review addressed the Accountability Standard Number 2, internal metaevaluation, which states that evaluators should use the Joint Committee on Standards for Educational Evaluations (1994) and other standards in order to examine the accountability of the evaluation design, procedures, data collection, and outcomes.

The logic model flow chart includes all of the practical steps needed for a program evaluation in addition to procedures that are distinctively related to some of the logic model limitations. The logic model flow chart includes negotiate evaluation terms; identify program design and the problem the program is trying to address; identify program theory; logic model development which include inputs, activities, outputs, and outcomes; data collection; data analyze including the ChiSquare test and other necessary tests as needed; data reporting; provide recommendations, and meta-evaluation.

\section{Procedures: Testing the Original and Newly Revised Logic Models}

The original logic model was completed by using the standard logic model procedures developed by United Way of America. This will include the development of the logic model by providing the programs inputs, activities, outputs, and outcomes. The newly revised logic model flow chart was followed step-by-step in the following order: negotiate evaluation terms; identify program design and the problem the program is trying to address; identify program theory; logic model development which include inputs, activities, outputs, and outcomes; data collection; data analysis including the Chi-Square test and other necessary tests as needed; data reporting; provide recommendations, and meta-evaluation. 


\section{ZSA-ZSA BOOKER}

Data for the learning community evaluation was obtained from the institutional Student Admissions and Records System (STARS) at a major midwestern urban university. It is composed of student demographic and academic information. STARS also includes the learning community cohort database. Students first year GPA on a 4.0 scale, and students' re-enrollment status was obtained through STARS. STARS is a university web-based application used to access university data for advising, retention, curriculum and program tracking (Baier, 2014).

\section{Participants}

The participants of interest for this study were first time, first year college students admitted and enrolled in the particular learning community during the following fall cohorts: Fall, 2007 ( $\mathrm{N}=3096), 2008(\mathrm{~N}=2797), 2009(\mathrm{~N}=2957)$, and 2010 $(\mathrm{N}=2613)$ semesters at a midwestern higher education institution. The learning community participants were in one of the following fall cohorts: Fall, 2007 $(\mathrm{N}=25), 2008(\mathrm{~N}=35), 2009(\mathrm{~N}=30)$, and $2010(\mathrm{~N}=20)$.

The learning community educational program used in this study included a total of $\mathrm{N}=110$ subjects. The following demographic information was collected from the subjects: gender, ethnicity, and age. Gender for the entire group of cohorts is $78(71 \%)$ female and $32(29 \%)$ male. Ethnicity for the group is $64 \%$ Black, $23 \%$ unknown, 8\% Hispanic, and 3\% White, and 2\% Asian. The age for the group includes $71 \% 18$ years old, 12\% 19 years old, 9\% 20 years old, and $8 \% 21$ years old. Participants represented were all high achieving academics from high school and represented local high schools near the area of the midwestern institution. An IRB was obtained in order to conduct this research because it includes data regarding human subjects.

\section{Research Design}

The main objective of this research was to discover which of the two logic model types, the original logic model or the revised logic model, was more effective according to the standards created by the Joint Committee on Standards for Educational Evaluation (1994). The evaluation of the learning community educational program was conducted as a non-experimental retrospective study in order to gauge the how time affects group changes. The design for this study is retrospective descriptive to look backward to locate information on the independent variables that help to explain the current differences on the dependent variables and to describe the characters of the study phenomenon (Johnson, 2001). 


\section{REVISED LOGIC MODEL FOR PROGRAM EVALUATION}

A summative meta-evaluation was conducted in order to determine if there is a statistically significant difference between the original logic model and the revised logic model, and will ultimately help to determine which logic model is more effective based on program evaluation standards and guidelines. A metaevaluation checklist will help to determine which evaluation standards were met for each of the two logic models.

\section{Data Collection/Analysis}

Data needed to perform the evaluation of the learning community was collected using STARS. Data collected from STARS included both learning community student. The Statistical Package for the Social Sciences for Windows (SPSS 23.0) was used. An alpha level of 0.05 was used as the significance level, which was used to determine whether to reject or fail to reject the null hypothesis.

Data was collected from STARS in order to understand student success, student's GPA and graduation status, was analyzed in order to determine the learning community's effectiveness. Chi-Square analysis was used to determine if there are statistically significant differences between learning community students with a $2.5 \mathrm{GPA}$ and higher and a 2.49 GPA and below at the midwestern higher education institution.

\section{Meta-Evaluation: Original and Revised Logic Models}

The meta-evaluation was used to determine the effectiveness of both logic models and will allow for a comparison which revealed the most effective model between the two. The meta-evaluations of both the original and newly revised logic models was conducted by using the standards from the Joint Committee on Standards for Education Evaluation (1994). Each evaluation standard was added to a metaevaluation checklist and both logic models were analyzed in order to determine their effectiveness.

The evaluation standards used in the meta-evaluation from the Joint Committee on Standards for Educational Evaluation (1994) include five categories which are: Utility, Feasibility, Proprietary, Accuracy, and Evaluation Accountability. There is a total of 30 standards represented in these five categories. The 30 standards were compared to each logic model by way of checklist, in order to determine which model is efficient, as noted in Figure 2. 


\section{ZSA-ZSA BOOKER}

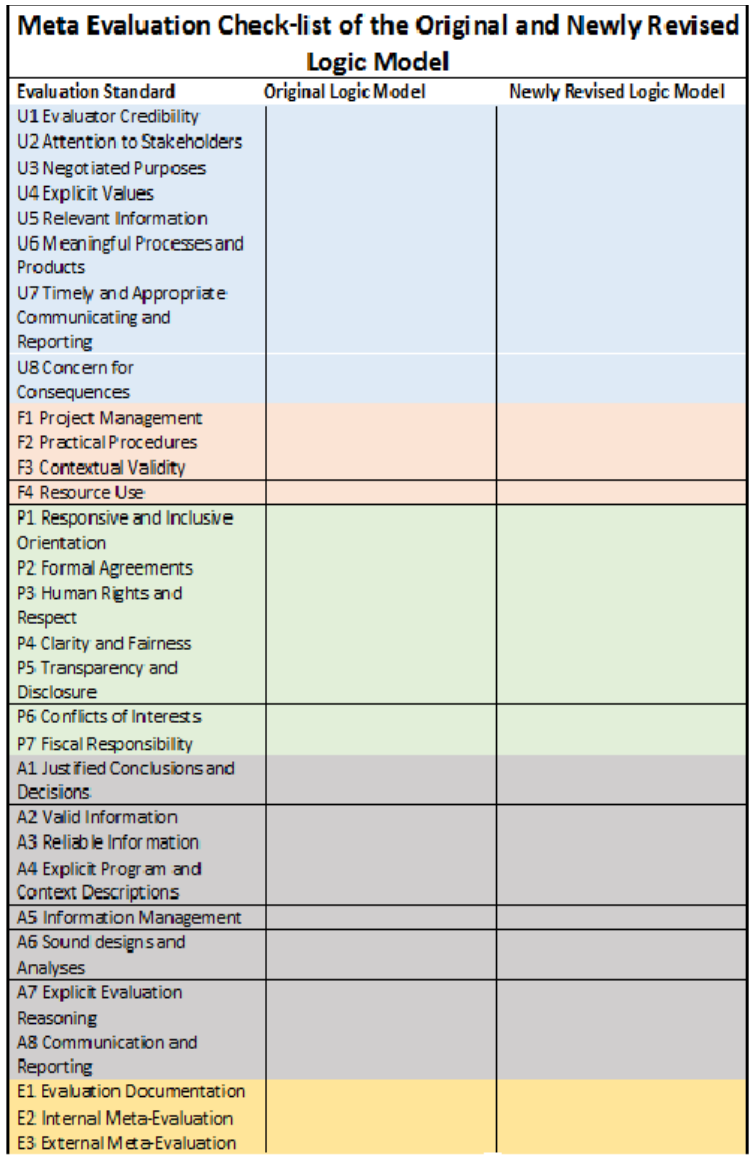

Utility Standards (8)

Feasibility Standards (4)

Proprietary Standards (7)

Accuracy Standards (8)

Evaluation Accountability Standards (3)

Figure 2. Meta-Evaluation Checklist of the Original and Newly Revised Logic Models: Based on the Joint Committee on Standards for Educational Evaluation (1994).

\section{Data Analysis}

The entries for both the original and revised logic model approach in Figure 2 was compared via a one-tailed Wilcoxon Rank Sum Test with nominal alpha set to 0.05 . It is a nonparametric alternative to the t-test, and is most useful when normality is violated. Monte Carlo research has shown it is a much more powerful test (Sawilowsky, 2005). 


\section{REVISED LOGIC MODEL FOR PROGRAM EVALUATION}

\section{Results}

The first research questions in this study was, "Are evaluation standard characteristics missing from the original logic model?" The Revised Logic Model was created based on the evaluation standards found within The Program Evaluation Standards from the Joint Committee on Standards for Educational Evaluation (1994) and Stufflebeam's (2001) Evaluation Models. Both of these resources indicated there were standards missing from the logic model that are seen in other questions and methods approaches.

Both the outcome/value added approach and case study approach included evaluation standard characteristics missing from the Theory-Based Approach, which include logic models. It was found that the following items were missing from the original logic model: Methods (Cross-Break Tables), Consideration for Contextual Influences, and Rejection of Artificial Cut-Scores.

The second research question in this study was, "What program evaluation characteristics, seen in other similar standardized models, help to make them more efficient and capable?" In order to help make the logic model more standardized and comparable to other questions and methods approaches the following characteristics were added: Chi-Square test, rejection of artificial cut-scores, consideration of contextual influences, logic model flow chart, and stakeholder interviews.

It was found that the original logic model needed revisions, having the following limitations and missing evaluation standards. Shown in Table 1 below are the limitations seen in the original logic model, the evaluation standards related to those limitations, and the revised logic model revisions established in order to change the original model and make it more standardized and effective. Note the limitations "No Relevant Information" and "No Accountability" were added to the list after observations of both models and the identification of insufficient evaluation standards.

The main research question was, "Will the logic model become more effective after improving limitations and reevaluating its evaluation standards and guidelines?" The meta-evaluation results from the original and newly revised logic models were used to conduct a d Wilcoxon Rank Sum Test to determine if there were statically significant differences between the meta-evaluation results for the original logic model and the newly revised logic model.

The total mean score for the revised logic model meta-evaluation was .933

while the mean score for the original logic model meta-evaluation was .267. The 


\section{ZSA-ZSA BOOKER}

Wilcoxon Rank Sum Test was statistically significant $(Z=-2.04$, exact one tailed $\mathrm{p}=.031)$.

Table 1. Logic Model Limitations, Insufficient Evaluation Standards, and Revisions

\begin{tabular}{lll} 
Limitations & Evaluation Standards & Revisions \\
\hline No Methods & Feasibility & Chi-Square Test \\
No Contextual Influences & Accuracy & Program Theory \\
No Rejection of Artificial Cut Scores & Accuracy & Research/Validation \\
Time Consuming \& Costly & Accuracy & Reject Artificial Cut Scores \\
No Relevant Information & Utility & Logic Model Flow-Chart \\
No Accountability & Evaluation Accountability & Stakeholder Interview \\
\hline
\end{tabular}

\section{Discussion}

Logic models have the potential to contribute greatly to educational programs as well as the field of program evaluation, with the addition of evaluation standards and research from Stufflebeam (2001). In consideration of the research found in Stufflebeam's (2001) Evaluation Models, the following additions were made to the revised logic model: Chi-Square test (which provides Cross-Break tables), the rejection of artificial cut scores, and the consideration of contextual influences. Given the program evaluation standards created by the Joint Committee on Standards for Educational Evaluation, the following additions were made: logic model flow chart, program theory identification, meta-evaluation. In this study, the revised logic model was shown to be more promising than the original logic model.

Theory-oriented evaluation models have become more recognized in program evaluations, and the logic model has been used widely because of this (Fitzpatrick et al., 2012). The objectives of this study were to transform the original logic model from being a static framework that is less amenable to change into a more dynamic and hence nimble evaluation model. This study helps to address the research found from Stufflebeam (2001) which indicated that program theory-based approaches, such as the logic model, were one of the worst in the field. Others, such as Suchman (1967), Langford (2010), and Weiss (1998), did not even consider the logic model a model at all, instead labeled it a framework: "The logic model does not dictate any prescribed method or evaluation, nor does it imply any kind of evaluation model" (Bolden, 2007, p. 57). However, Stufflebeam, along with many others, did not discuss how to improve the logic model, and that is what is missing from the 


\section{REVISED LOGIC MODEL FOR PROGRAM EVALUATION}

literature. This study, therefore, was designed to serve as a catalyst to more research on this topic and improvements in the field of program evaluation and research.

The logic model findings from this research will help to promote research and program evaluation dialogue that will ultimately contribute to improving the field of program evaluation. Based on the findings from this study, further research could be done in many areas in order to help promote a more accurate logic model. Further investigation could be made in order to discover how other models could be improved. For example, Stufflebeam mentioned that there were four other approaches that he found needed improvements which included the following: politically controlled, public relations, accountability, and clarification hearings. Further investigation could be conducted in order to test methods that fit with these approaches in order to improve them.

\section{Acknowledgments}

This paper is developed in part from the author's unpublished dissertation (Booker, 2016), and elements throughout are derived from that work.

\section{References}

Baier, S. T. (2014). The Role of academic factors, self-efficacy, mentoring relationships, and learning communities in persistence and academic success of freshmen college students (Paper 870) [Doctoral Dissertation, Wayne State University]. Digital Commons at Wayne State University.

https://digitalcommons.wayne.edu/oa_dissertations/870/

Bolden, K. F. (2007). Applying Logic Modeling to the Higher Education Accreditation Process (Publication No. 3313774) [Doctoral Dissertation, University of New Orleans]. ProQuest Dissertations \& Theses Global.

Booker, Z-Z. (2016). A New Logic Model For Change (Paper 1627) [Doctoral Dissertation, Wayne State University]. Digital Commons at Wayne State University. https://digitalcommons.wayne.edu/oa_dissertations/1627/

Chen, H. T. (2015). Practical Program Evaluation: Theory-Driven Evaluation and the Integrated Evaluation Perspective (2nd Ed.). Thousand Oaks, CA: Sage Publications, Inc.

Dwyer, J. J. M. \& Makin, S. (1997). Using a program logic model that focuses on performance measurement to develop a program. Canadian Journal of Public Health, 88(6), 421-425. https://doi.org/10.1007/bf03403919 


\section{ZSA-ZSA BOOKER}

Fitzpatrick, J. L., Sanders, J. R., \& Worthen, B. R. (2012). Program evaluation: Alternative approaches and practical guidelines (4th Ed.). Boston, MA: Pearson.

Frechtling, J. A. (2007). Logic Modeling Methods in Program Evaluation. San Francisco, CA: Jossey- Bass.

Johnson, B. (2001). Toward a new classification of nonexperimental quantitative research. Educational Researcher, 30(2), 3-13.

https://doi.org/10.3102/0013189x030002003

Joint Committee on Standards for Educational Evaluation. (1994). The Program evaluation standards: How to Assess Evaluations of Educational Programs (2nd Ed.). Thousand Oaks, CA: Sage Publication, Inc..

Langford, L.L. (2010). The Development and testing of an evaluation model for special education (Publication No. 3417501) [Doctoral Dissertation, The University of Texas at Austin]. ProQuest Dissertations \& Theses Global.

Office of Assessment, Evaluation, and Research Services (OAERS). (n.d.). Program Evaluation Resource Center. School of Education, Department of Educational Research Methodology, University of North Carolina at Greensboro. Retrieved February 11, 2015. http://erm.uncg.edu/oaers/methodology-resources/program-evaluation/

Polush, E. Y. (2007). Program Theory of a USDA Grants Program for use in Evaluation Based on Quantitative Content Analysis and Oral History Analysis (Publication No. 3283094) [Doctoral Dissertation, Iowa State University]. ProQuest Dissertations \& Theses Global.

Renger, R. \& Titcomb, A. (2002). A Three-step approach to teaching logic models. American Journal of Evaluation, 23(4), 493-503.

https://doi.org/10.1177/109821400202300409

Sawilowsky, S. (2005). Misconceptions Leading to Choosing the t Test Over the Wilcoxon Mann-Whitney Test for Shift in Location Parameter. Journal of Modern Applied Statistical Methods, 4(2), 598-600. https://doi.org/10.22237/jmasm/1130804700

Stake, R. E. (1976). Evaluating educational programs: The Need and the response. Paris, France: Organization for Economic Cooperation and Development.

Stufflebeam, D. L. (2001). Evaluation models. New Directions for Evaluation, 89, 7-98. https://doi.org/10.1002/ev.3

Suchman, E. A. (1967). Evaluative Research. Russel Sage Foundation.

United Way of Greater Richmond \& Petersburg. (n.d.). A Guide to developing an outcome logic model and measurement plan. Retrieved February 15, 2015. http://www.yourunitedway.org/sites/uwaygrp.oneeach.org/files/Guide_for_Logic_Model s_and_Measurements.pdf 


\section{REVISED LOGIC MODEL FOR PROGRAM EVALUATION}

Weiss, C. H. (1998). Evaluation: Methods for Studying Programs and Policies. Upper Saddle River, NJ: Prentice Hall.

W.K. Kellogg Foundation. (2004). Using logic models to bring together planning, evaluation, and action: Logic model development guide. Battle Creek, MI: W.K. Kellogg Foundation.

https:/www.bttop.org/sites/default/files/public/W.K.\%20Kellogg\%20LogicModel.pdf

Wholey, J. S., Hatry, H. P., \& Newcomer, K. E. (2010). Handbook of practical program evaluation (3rd Ed.). San Francisco, CA: Jossey-Bass. 